\title{
Prevention of fracture-related infection: a multidisciplinary care package
}

\author{
Willem-Jan Metsemakers ${ }^{1,2}$ (1) $\cdot$ Jolien Onsea $^{1,3} \cdot$ Emilie Neutjens $^{4} \cdot$ Ester Steffens $^{3}$. \\ Annette Schuermans ${ }^{3,5}$ - Martin McNally ${ }^{6}$ - Stefaan Nijs ${ }^{1,2}$
}

Received: 23 April 2017 / Accepted: 8 August 2017 / Published online: 22 August 2017

(C) The Author(s) 2017. This article is an open access publication

\begin{abstract}
Fracture-related infection (FRI) remains a challenging complication. It may result in permanent functional loss or even amputation in otherwise healthy patients. For these reasons, it is important to focus attention on prevention. In treatment algorithms for FRI, antibiotic stewardship programmes have already proved their use by means of a multidisciplinary collaboration between microbiologists, surgeons, pharmacists, infectious disease physicians and nursing staff. A similar approach, however, has not been described for infection prevention. As a first step towards achieving a multidisciplinary care package for infection prevention, this review summarises the most recent guidelines published by the World Health Organization (WHO) and US National Institutes of Health Centers for Disease Control and Prevention (CDC), primarily focusing on the musculoskeletal trauma patient. The implementation of these guidelines, together with close collaboration between infection control physicians, surgeons, anaesthesiologists and nursing staff, can potentially have a beneficial effect on the
\end{abstract}

Willem-Jan Metsemakers

willem-jan.metsemakers@uzleuven.be

1 Department of Trauma Surgery, University Hospital Leuven, Leuven, Belgium

2 Department Development and Regeneration, KU Leuven University of Leuven, B-3000 Leuven, Belgium

3 Department of Infection Control and Epidemiology, University Hospitals Leuven, Leuven, Belgium

4 Department of Biomedical Sciences, Catholic University Leuven, Leuven, Belgium

5 Department of Public Health and Primary Care, KU Leuven University of Leuven, B-3000 Leuven, Belgium

6 The Bone Infection Unit, Nuffield Orthopaedic Centre, Oxford University Hospitals, Oxford, UK rate of FRI after musculoskeletal trauma surgery. It must be stated that most evidence presented here in support of these guidelines was not obtained from musculoskeletal trauma research. Although most preventive measures described in these studies can be generalised to the musculoskeletal trauma patient, there are still important differences with nontrauma patients that require further attention. Future research should therefore focus more on this very defined patient population and more specifically on FRI prevention.

Keywords Fracture-related infection - Prevention - Infection prevention $\cdot$ Multidisciplinary care package $\cdot$ Musculoskeletal trauma surgery

\section{Introduction}

Fracture-related infection (FRI) not only accounts for a high morbidity and mortality rate, it has a substantial socioeconomic impact compared with musculoskeletal trauma patients who do not develop this complication [1-4]. The incidence of infection after internal fixation of closed fractures is reported to be 1-2\% but can reach $30 \%$ in cases of open fractures [5-7]. As the consequences of such infection can be life-changing for the patient due to permanent functional loss or amputation of the affected limb, patient quality of life (QoL) and functional status also decrease [8-10]. To tackle these issues, it seems highly important to focus on infection prevention and improve outcome. Care bundles, a concept developed by the Institute for Healthcare Improvement (IHI) (Cambridge, MA, USA), are small sets of evidence-based practices to reduce certain complications like infections (e.g. ventilator-associated pneumonia, urinary tract infection, postoperative wound infection, etc.). However, care bundles only concern four or five key aspects to improve patient outcome. The review presented here envisages a 
multidisciplinary care package for infection prevention, including pre-, peri- and post-operative phases. A multidisciplinary care package would ideally implement co-operation between surgeons, infection control (ID) physicians, nurses and anaesthesiologists. Successful antibiotic stewardship programmes for treating infection apply a similar approach, with collaboration between microbiologists, surgeons, clinical pharmacists and ID physicians [11, 12].

In this review, we emphasise the importance of a multidisciplinary care package focusing on infection prevention in the musculoskeletal trauma patient. As a first step towards establishing such a package, we describe infection prevention measures and guidelines for the pre-, peri- and post-operative phases. These measures are based on guidelines of the US National Institutes for Health Centers for Disease Control and Prevention (CDC) [13, 14], published by the World Health Organization (WHO) [15] and on data available from translational research and clinical studies to illustrate the current research directions in the field of musculoskeletal trauma surgery.

\section{Definition}

Despite the fact that FRI can have serious consequences, no uniform definition has yet been developed $[16,17]$. We sometimes use the $\mathrm{CDC}$ guideline to prevent surgical-site infection (SSI), which distinguishes between superficial incisional, deep incisional and organ/space infections [13]. However, this guideline was not specifically developed for fracture patients [16], and for this reason, the term SSI is used in this review for lack of a clear alternate definition, although the authors are aware of the need for a consensus definition of FRI [18].

\section{Risk factors for FRI}

The risk of developing an FRI is multifactorial. Patient-related risk factors include, for example, smoking, which can delay wound healing and increase the risk of infection. Other factors, such as obesity, extremes of age, diabetes mellitus, use of steroid or immunosuppressant drugs, malnutrition and a prolonged preoperative hospital stay, increase the risk of colonisation with a resistant hospital-acquired bacterial strain. Long procedure time is a risk factor, although most supporting evidence was obtained from studies performed in elective, nontrauma patients [8].

The National Nosocomial Infections Surveillance (NNIS), a tool that reflects the risk of developing an infection, is calculated based on the American Society of Anesthesiologists (ASA) score (reflecting the impact of comorbidities), duration of surgery and wound class. An ASA score $>2$ indicates a patientrelated risk factor for infection $[8,13,17,19,20]$, and SSI rate is strongly correlated with a higher NNIS score [21]. Other risk factors include lack of appropriate antibiotic prophylaxis, in which appropriate timing and correct choice of antibiotic must be taken into account, and emergency procedures [19]. McPherson et al. established that the host (medical and immune) status plays an important role in the development of infections. Patients who are medically compromised or critically ill (host grade B or C) will most likely be unable to fight an infection systemically or locally. If host status cannot be improved by treatment, this may lead to poor outcomes, with high infection rates, amputation of affected limbs or systemic sepsis resulting in mortality, emphasising the need for infection prevention in this compromised patient group [22, 23]. However, in trauma patients, there may be very limited time available for patient optimisation prior to fracture surgery.

\section{Preventive measures}

Preventive measures regarding SSIs can be divided into preoperative, peri-operative and post-operative phases. Most measures listed below are in line with the most recent CDC and WHO guidelines $[13,15]$ and focus primarily on the musculoskeletal trauma patient.

\section{Pre-operative prevention measures}

\section{Staphylococcus aureus colonisation}

Up to one third of the population is, although asymptomatically, colonised with Staphylococcus aureus. The nares are most frequently and most abundantly colonised by this pathogen [24]. There is a distinction between methicillin-sensitive (MSSA) and methicillin-resistant (MRSA) S. aureus. Both types are equally virulent and can potentially cause an SSI. An important difference is that for SSIs caused by MRSA, treatment options are reduced, causing increased morbidity, longer hospital stays and consequent increased healthcare costs [25]. Because of this, many hospitals focus solely on MRSA carriers. In a prospective study of 440 trauma patients with hip fractures, the incidence of MRSA colonisation was $5.2 \%$, with the nose being the site most frequently colonised. Important to note is that these patients were generally older, which is also a risk factor for MRSA colonisation and SSI. Other risk factors identified for colonised patients are the presence of surgical wounds, pressure ulcers, intravenous catheters, recent ICU admission and previous hospital admission within the last six months [26]. Nixon et al. found corresponding results, with $5.8 \%$ of their trauma patients being carriers of MRSA upon admission [27]. Another prospective study performed by Walley et al. showed an incidence of $12 \%$ upon admission. The prevalence of MRSA-positive screening was $17 \%$ in their study [28]. In countries with a low MRSA prevalence (e.g. Scandinavia, The Netherlands, Western Australia), healthcare workers are frequently screened. This 
is generally not the case in other countries (i.e. UK, USA, Belgium), which might - in combination with patients' relatives being possible carriers - contribute to the interhospital spread of MRSA [27, 29].

On the other hand, the impact of an infection caused by MSSA on the trauma patient should not be underestimated. Combined screening for MRSA and MSSA has thus been suggested because a reduced risk of infection caused by $S$. aureus might outweigh the extra costs of additional screening [30]. Several studies provided evidence for the value of pre-operative screening for $S$. aureus and subsequent decolonisation in the reduction of hospital-acquired SSIs caused by this pathogen $[24,31]$. In cases with a positive culture for $S$. aureus (MSSA or MRSA), a decolonisation using either mupirocin or chlorhexidine $1 \%$ nasal ointment is effective. In addition, for skin decontamination, a soap containing chlorhexidine (Hibiscrub®) can be used, combined with a mouth wash containing chlorhexidine (Perio-aid®) as an oral antiseptic [32-34].

The WHO did not provide guidelines concerning screening methods; nevertheless, they recommend decolonisation in patients positive for $S$. aureus, especially in cardiothoracic and orthopaedic surgery [15]. In elective cases, we believe this approach is advisable, but this might be difficult to achieve in emergency settings (i.e. fracture patients) where the outcome can be dependent on immediate surgery [26].

\section{Hand hygiene}

Hand hygiene is a very important factor for infection control and is included in the WHO guidelines [35]. A major transmission route of micro-organism causing nosocomial infections are contaminated hands of healthcare workers [36, 37]. Staff must wash their hands with water and neutral soap for at least 15 seconds at the beginning of the work shift, after each break and after visiting the toilet [8, 37, 38]. Furthermore, healthcare workers should disinfect their hands with an alcohol-based antiseptic before and after each patient contact, after contact with the patient's surroundings, after exposure to bodily fluids and mucous membranes and before a clean or aseptic procedure [35, 36]. There is a lack of evidence concerning the link between the presence of nail polish and finger rings and the risk of SSI [39]. However, as they may have an influence on hand hygiene, different guidelines confirm that all healthcare providers should keep nails short and may not wear artificial nails, nail polish or any jewelry on hands and arms because they may be a source of infection. In addition, jewelry can perforate sterile gloves $[13,35,40$, 41]. The compliance for hand hygiene of healthcare workers remains low, despite educational efforts. Therefore, to increase compliance, behavioral changes are necessary [36].

In pre-operative hand hygiene, it is of critical importance that all members of the surgical team who are in direct contact with the sterile field or instruments disinfect their hands before they put on sterile gloves and gown $[8,13,35,37]$. This is done to reduce microflora on the hands of the surgical team to below baseline level [8]. In the past, healthcare workers performed a hand scrub with an antimicrobial soap with broadspectrum activity; directives now recommend doing a hand rub with an alcohol-based solution [8, 37, 38, 42]. While both techniques are suitable, a surgical hand rub with an alcoholbased solution is less time consuming, has fewer side effects (less skin irritation and dermatitis) and generally carries no risk of recontamination by the rinsing water [37, 43, 44]. In case of the surgical rub, Kampf et al. showed that a hand rub with Sterillium ${ }^{\circledR}$ for only 60 seconds does not reach the required efficacy, and an additional 30 seconds are essential to reach full efficacy [45]. Hence, it is essential that healthcare worker respects the 90 seconds rubbing time required to perform the procedure. Using an adjustable clock can be helpful to achieve this. Other factors - namely, rubbing technique, skin condition and techniques used for drying and gloving are also important with respect to the effectiveness of the surgical rub $[13,35]$.

\section{Surgical-site preparation}

Hair removal Hair removal by shaving prior to surgery is associated with a higher prevalence of SSIs. Therefore, if it does not interfere with the surgery, hair should not be removed $[13,42]$. If necessary, the WHO encourages hair removal with a clipper but strongly discourages shaving, as this might create microscopic cuts in the skin, leading to microbial contamination and thereby SSI. In addition, if performed, pre-operative hair removal at the incision site should be done outside the operating room (OR) [13, 15, 46, 47].

Pre-operative washing Pre-operative patient bathing or showering reduces bacterial load on the skin. Generally, an antimicrobial soap is used; however, according to the WHO, there is no scientific evidence that antimicrobial soap is better than plain soap in reducing the infection risk [15]. Of course, this measure is limited to elective surgery because in urgent settings (e.g. polytrauma patients, severe open fractures), preoperative patient bathing or showering may not be possible. In these cases, it might be beneficial to undertake site-specific washing pre-operatively. Although data regarding this topic in musculoskeletal trauma patients is again lacking, we would advise this as routine practice.

Skin antisepsis Pre-operative skin preparation is an important preventative measure to reduce the number of microorganisms at the surgical incision site $[8,48]$. The WHO recommends the use of an alcohol-based antiseptic solution with chlorhexidine gluconate (e.g. chlorhexidine-alcohol $70 \%$ with azorubine), rather than an aqueous antiseptic solution like 
povidine-iodine [15]. Different studies suggest that chlorhexidine-alcohol is more efficient in reducing SSI than a water-based povidine-iodine solution, probably because of a more rapid action, persistent activity and a residual effect [48-51]. A limitation of these studies is that they compare an alcohol-based solution (containing chlorhexidine) with an aqueous solution (containing povidine-iodine). Next to chlorhexidine-alcohol $70 \%$ with azorubine, an antiseptic frequently used is iodine-alcohol $1 \%$. Historical data comparing chlorhexidine-alcohol with alcohol-based iodine found no difference between them [52, 53]. Recently, Broach et al. compared chlorhexidine-alcohol with iodine povacrylex-alcohol in a noninferiority trial. The authors decided in favor of chlorhexidine-alcohol, but further studies are necessary to confirm their conclusion [54]. None of the previous studies were performed in trauma patients.

Although different techniques can be used to perform skin antisepsis (i.e. applying the antiseptic in concentric circles), it is crucial to administer the agent from a clean zone (e.g. the site of incision) to a dirty zone (e.g. umbilicus, axilla or groin). In addition, the prepared area must be large enough to extend the incision or to create drain sites if necessary. The contact time, which is the time by which skin antisepsis is actively performed by surgical staff, depends on the type of product and is specified in the package insert. For alcohol-based solutions, contact time must at least be $30 \mathrm{~s}$. To avoid desterilisation, we recommend that the person who applies skin antisepsis not (yet) be dressed in sterile surgical attire. Moreover, to obtain optimal efficiency and avoid skin burns and loss of product, healthcare workers must also respect the dry time of the antiseptic agent before placing the surgical drapes [8, 13, 42].

\section{Antibiotic prophylaxis}

Antibiotic prophylaxis is known to reduce SSI [42]. Different studies identified that failure of antibiotic administration before surgery is a risk factor for infection $[36,55]$. Boxma et al., in a large randomised clinical trial, showed that an adequate singledose antibiotic prophylaxis is effective to reduce the incidence of implant-related infections after surgery for closed fractures [56]. This was confirmed by a Cochrane analysis [57]. As the aim of prophylactic antibiotic administration is to obtain adequate tissue concentrations by the time of incision, the timing of administration is key $[15,58]$. Depending on type of surgery, the antibiotic should be administered within 120 minutes before the incision, thereby taking the half-life of the drug into account. For trauma surgery, the antibiotic should be administered 15-60 minutes before incision [15, 42].

Next to correct timing, using an appropriate antibiotic is important. The routine use of a broad-spectrum antibiotic like a first- or second-generation cephalosporin has been established in musculoskeletal trauma surgery [58]. Antibiotic prophylaxis should normally be single dose; however, in situations that reduce the antimicrobial's half-life, the antibiotic should be redosed [59]. These situations arise with excessive blood loss and burn wounds. In addition, in complex ostheosyntheses and arthroplasties, redosing the antibiotic is more effective than a single dose, and antibiotic treatment in these cases should be continued for 24 hours $[60,61]$. For these complex surgeries, which require quite some time, it is standard practice to redose the antibiotic once the duration of surgery exceeds two half-lives of the antibiotic. For example, cefazolin should be redosed every three hours during surgery. On the other hand, intra-operative redosing may not be appropriate for patients with renal impairment, as this condition can increase the elimination time of most antibiotics [62]. Finally, antibiotic prophylaxis should be individually adapted for each patient, taking into account weight, allergies and medical history and the antimicrobial's half-life [63]. The choice of antibiotic must be based on an understanding of organisms likely to cause infection after musculoskeletal trauma surgery. In trauma patients who have undergone recent emergency surgery or have been in the ICU, prior to a definitive fracture reconstruction, antibiotic prophylaxis may need to be altered to include cover for hospital-acquired pathogens during the second surgery.

In case of open fractures, the evidence is less clear. Although it is key that systemic prophylaxis is administered - preferably as early as possible — due to the failure of clinical studies to demonstrate clear evidence for any single regimen, no clear guideline regarding optimal prophylaxis duration for open fractures has been established. Currently, there is no evidence that extending antibiotic treatment beyond 24 48 hours, even for type II and III open fractures, decreases infection rates [64-66]. Rodriguez et al. investigated the implementation of an evidence-based protocol for antibiotic prophylaxis in open fractures. They found that a short course of antibiotics with a narrow spectrum, thereby avoiding the use of broad-spectrum aminoglycosides and glycopeptides, does not increase the risk of soft tissue and skin infections after an open fracture [66]. Furthermore, the authors showed that improved antibiotic stewardship reduces such risks as nephrotoxicity and the emergence of antimicrobial resistance with glycopeptide and aminoglycoside use. Again, this proves that FRI prevention and treatment should be addressed by a multidisciplinary team.

In case of complex open fractures, systemic antibiotics alone are often not sufficient because the surrounding tissues and blood vessels - by which systemic antibiotics would normally reach the tissue-implant interface - may be damaged as well. Studies show that local administration of antibiotics could have a positive influence on infection prevention [67-69]. Local prophylaxis can be administered by cement spacers, which are made of polymethyl methacrylate (PMMA), collagens, coatings (e.g. antibiotic-coated tibial nails) and hydrogels [69]. 
It seems needless to say that future research on infection prevention, specifically in open fractures, is urgently required.

\section{Perioperative prevention measures}

The operation room environment, including surgical attire, ventilation, (sterilisation of) surgical instruments and traffic patterns in and out, can have an influence on the perioperative risk of infection $[8,13]$.

\section{Operative environment}

The probability of SSI is directly related to the number of bacteria reaching the incision. Hence, every peri-operative measure lowering bacterial load in the OR should be supported [58].

Surgical attire Surgical attire consists of scrub suits (pants and shirt with short sleeves, with cuffs on arms and ankles), washable shoes, caps, and surgical masks and (sterile) gloves and gowns [38]. Since ears, hair and scalp are a common source of $S$. aureus, this type of attire is used to minimise exposure of the patient to skin, mucous membranes and hair of the surgical team members, and it forms a barrier between the patient and the surgical team. Lastly, they are important to maintain the sterile field around the patient $[8,13,70]$. The surgical attire should be changed after it becomes visibly soiled, except for the surgical mask, which should be changed after each operation or every three to four hours [13, 38]. Wearing shoe covers in the operation room is not recommended, as it has not been proven that they decrease the number of SSIs [13]. Although implementation of surgical attire reduces bacterial load in the OR, there is no evidence for a relationship between these measures and the prevalence of SSI [70]. Furthermore, the effect of surgical masks on SSI reduction remains unknown [71, 72]; however, as they prevent transmission of droplets from coughing or sneezing, and because they act as a personal protection measure, it is still recommended to use a surgical mask during surgery.

Some studies have evaluated the use of surgical helmet systems (SHS) and full-body surgical suits. Compared with conventional surgical attire, Young et al. reported in favour of the full-body suit, while Hooper et al. provided evidence for higher infection rates wearing this type of attire. This might be due to the surgeon having a false sense of security or the exhaust systems expelling air near the incision site [73, 74]. It appears that wearing the SHS does not reduce the chance of contamination and may even result in higher rates of deep infection [73]. We therefore recommend wearing the conventional surgical attire unless in situations where the surgical staff's safety (e.g. in case of HIV patients) outweighs the drawbacks of this particular type of attire.
Surgical hand hygiene Regarding surgical hand hygiene, bacterial recolonisation of healtcare workers' hands increases with duration of surgery. Thus, the surgeon can become a continuous source of contamination regardless of compliance with proper scrubbing or rubbing and gloving. After five hours of surgery, the surgeon's hands show an equal or even higher bacterial colonisation compared with pre-scrub or prerub colonisation. It should therefore be recommended to repeat the scrub or rub procedure depending on duration of the surgical procedure [75]. In addition, it must be emphasised that surgical gloves do not provide absolute protection against contaminants [76]. Especially in trauma and orthopaedic surgery, unnoticed perforations are common, with perforation rates between $3.6 \%$ and $21 \%$. The risk of glove perforation increases with the duration of wear. The passage of bacteria through these perforations should therefore not be underestimated [77]. To reduce the risk of contamination, Hübner et al. recommend a routine glove change at least every 90 minutes [76]. As this can be quite laborious, an important alternative used especially in trauma and orthopaedic surgery is the double-gloving procedure, or using two pairs of standard sterile surgical gloves, or using indicator-system gloves. The advantage of the indicator system is that a perforation can be noticed relatively quickly $[76,78]$. The WHO did not formulate any recommendations concerning double gloving or glove changing during surgery, as studies assessing these procedures in relation to SSI outcome are scarce [15]. Nonetheless, in trauma surgery, it is common practice to double glove, and we believe that, particularly in longer procedures, re-scrubbing or re-rubbing is indicated.

Ventilation system Most ventilation systems in the OR produce vertical laminar (or unidirectional) airflow at positive pressure. This positive pressure will prevent air flowing from less clean areas (e.g. rubroom, corridor, etc.) to the clean areas (ORs) [13]. The ultraclean air is introduced at the ceiling of the OR and flows vertically towards the floor over the aseptic region, which consists of the incision site and surroundings under the plenum. The aim of the laminar airflow system is to decrease the bacterial load and consequently minimise the risk of SSIs $[8,13,79]$. The laminar airflow system is equipped with high-efficiency particulate air (HEPA) filters, which filter the recirculated air $[13,38,79]$. The movement and presence of staff in the OR may negatively influence the laminar flow, so the number of people in the OR must therefore be minimised [13, 80, 81]. Also, the doors of an OR must be closed as much as possible, because every time the door opens, the pressure drops and turbulence in air movements occur, contributing to wound contamination [80]. To reduce the frequency of door openings, Birgand et al. suggest a more practical storage of frequently used materials, advanced communication systems and an improved organisation of surgical team shift changes [79, 82]. 
Many studies have reported the benefits of a laminar airflow installation [83-86]. Interestingly, recent studies contradict these benefits, and the use of laminar airflow to reduce the risk of SSIs in orthopaedic surgery is currently being discouraged by the WHO. A possible explanation for this is that the layout of the OR, which is generally not standardised across hospitals, plays an important part in these findings. That is, everything obstructing the vertical airflow can cause turbulence, which in turn can produce areas at risk for contamination and therefore infection. Second, these systems are highly sophisticated, high maintenance and expensive. To obtain full efficacy, staff compliance to theatre protocols and frequent replacement of air filters and maintenance is of critical importance [87]. In low-resource settings in particular, this can be problematic [15].

Surgical instruments are expected to be sterile, as are the trays that carry them. However, as described above, there is a direct correlation between exposure time to the OR environment and traffic (e.g. during installment of the patient) and bacterial contamination. It is therefore recommended to leave sterile trays unopened until they are needed or to cover them with a sterile cloth to minimise exposure to contaminants [88].

Adhesive drapes The use of plastic adhesive drapes is another measure taken during surgery to prevent SSIs. They are used to protect the wound from organisms that may be present on the patient's skin. Adhesive drapes can be either plain or impregnated with an antimicrobial agent like iodine [89]. In its new guidelines, the WHO is rather hesitant towards the use of adhesive drapes with or without antimicrobial agents [15]. Moreover, the main outcome of a Cochrane analysis comparing plastic adhesive drapes with and without iodine was that plain adhesive drapes are not associated with a reduced risk of developing SSIs, and some studies even mentioned an increased risk of infection [89]. A possible explanation is that adhesive drapes cause excessive moisture, which might encourage bacteria in hair follicles to migrate to the surface. Also, not using drapes was associated with a lower risk of SSI, which can probably be explained by the fact that the skin is already decontaminated properly before incision, leaving an infection originating from the skin unlikely [89]. Removal of drapes may cause skin tears as well, which in turn is a risk for bacterial contamination. When using iodine-impregnated drapes, the risk of infection was comparable with that when no drapes were used [89]. In musculoskeletal trauma patients, and especially in open fracture cases, we currently do not advise the use of these plastic adhesive drapes.

\section{Surgical technique}

The surgical technique is an important factor in infection prevention, especially for trauma patients. It has been suggested that electrocautery for incision provides a better esthetical result, causes less bleeding and reduces pain scores compared with incisions with a scalpel. However, when both were compared regarding SSI rates, they showed comparable results [90]. Devitalised tissue should be removed during debridement and vital tissue should be handled with care [91], especially in musculoskeletal trauma, where there is already some degree of soft tissue damage present.

\section{Patient-specific measures}

Normothermia Hypothermia can have several adverse effects on trauma patients, especially on patients with multiple trauma. In particular, it can potentially disturb haemostasis, leading to uncontrolled coagulopathy and haemorrhage, which is especially important in trauma patients. Furthermore, hyperglycaemia can occur in trauma patients with mild hypothermia as a result of catecholamine release. Insulin treatment in these patients can result in a hypoglycaemic patient during rewarming. Also, drug elimination times (e.g. of vecuronium, benzodiazepines, alcohol) are prolonged in mild hypothermic patients, which in itself might potentiate the already present hypothermia [92]. Peri-operative hypothermia can thus result from exposure to the surgical environment, to the effects of anaesthetic agents or to certain drugs [15, 93]. Furthermore, hypothermia affects leukocyte migration, neutrophil phagocytosis and cytokine production, causing a depression of the immune system and therefore a delay in wound healing [94-96]. Until recently, the hypothesis was that these consequences - impaired immune function and delayed wound healing - increase the risk of SSI $[67,95,96]$. Brown et al. recently countered this hypothesis, as they found no significant correlation between the development of SSI and perioperative hypothermia. They point out that studies supporting the association between hypothermia and SSI often used multiple definitions for hypothermia, as well as single temperature measurement time points as variables. Their results were consistent with other recent studies investigating the importance of peri-operative normothermia [97]. Nonetheless, given the other adverse effects of hypothermia on trauma patients, frequent peri-operative monitoring of temperature to avoid hypothermia is advisable. Peri-operative use of warming devices aiming for a core body temperature of $>36{ }^{\circ} \mathrm{C}$ is also recommended by the WHO [15]. However, in this guideline, there is no recommendation regarding warming method. Different devices, forced-air warming or intravenous fluid warmers can be used to maintain body temperature $[95,96]$. The forced-air warmers are connected to specialised blankets with perforations on the underside through which the warm air can blow onto the patient's skin (e.g. Bair Hugger) [79]. These forcedair warmers are a potential risk for contamination originating from the pump and air-hose system [93, 98]; they may also have a disruptive impact on clean airflow patterns over the surgical site [98, 99]. Hence, forced-air warmers may 
contribute to an increased risk for SSIs, and this is a topic of ongoing research [93]. We advise that if these devices are used in a trauma setting, the patient should first be surgically draped before the warm air is blown into the system. A possible alternative to forced-air warmers is conductive fabric warming, which is equally effective in preventing hypothermia [99].

Normoglycaemia Hyperglycaemia is a short-term risk factor for developing post-operative infections. Therefore, it is important to keep glucose concentrations $<200 \mathrm{mg} / \mathrm{dl}$ during surgery. Patients with diabetes mellitus have an increased susceptibility for SSI [100], and tight glycaemic control in these patients has a positive effect on peri-operative mortality and morbidity rates. The use of protocols for intensive perioperative blood glucose monitoring is recommended by the WHO [15]. However, this recommendation should be treated with caution, as the incidence of hypoglycaemia has increased because of hyperglycaemia control being too tight. Frequent blood glucose monitoring can therefore be beneficial [101].

\section{Peri-operative wound management}

Surgical debridement and irrigation In case of open fractures, appropriate surgical wound debridement is necessary. Damaged, devitalised tissue and foreign material should be removed, as they constitute a favourable environment for microorganisms. For extensive open-fracture injuries, it is appropriate to repeat surgical debridement after 24-48 hours until a clean wound with viable tissue is obtained [102]. The goal of surgical irrigation is to reduce bacterial concentration and remove foreign bodies from the wound. The use of wound irrigation has been established by several studies, but there remains no consensus on the appropriate method to perform this technique (i.e. type of solution and pressure) $[64,91,103$, 104]. Regarding type of solution: several studies provide evidence for the toxicity of undiluted antiseptic solutions on host cells $[91,103,105,106]$. Otherwise, diluting the active component of an antiseptic like povidone-iodine can diminish cytotoxic effects without losing its bactericidal effect [107]. In recently published CDC recommendations for SSI prevention, the use of aqueous iodophor solutions for intraoperative irrigation of deep or subcutaneous tissues is recommended [14]. The CDC based this recommendation on two randomised controlled trials performed in patients who underwent clean spine surgery [108, 109] and on two randomised controlled trials performed in patients who underwent clean-contaminated, contaminated or dirty open abdominal surgery $[110,111]$. Again, it should be noted that these studies were not performed in musculoskeletal trauma patients, and specifically not in patients with an open fracture, where there is already serious damage to the local host environment. Currently, no data is available on the optimal type of irrigation and pressure to use in immunocompromised patients.

With respect to the type of irrigation pressure, the Fluid Lavage of Open Wounds (FLOW) trial recently showed that the use of low to very low pressure is the method of choice for irrigation in open fracture cases. Although no differences were found regarding type of pressure, surgical irrigation with highpressure lavage might anticipate bacterial seeding into the intramedullary canal, increasing wound bacterial counts at 48 hours after irrigation and compromising the bone-healing process [91, 103, 112-114]. Furthermore, the FLOW trial showed that irrigation with normal saline obtained better results than irrigation with a soap solution [114]. Therefore, based on literature data, we suggest rinsing the open fracture wound at low to very low pressures with normal saline (irrespective of the degree of contamination). The combination of early antibiotic treatment, surgical debridement and irrigation can effectively reduce micro-organisms present in the openfracture wound [102].

Finally, it is important to note that in open-fracture cases, the value of routine wound cultures before surgical debridement, which was standard practice prior to the 1980s, is currently being questioned. There is also no evidence supporting the value of wound cultures taken during initial surgicalwound debridement $[63,64]$. We would therefore discard this practice.

Wound closing A surgical wound can be closed primarily, left open to be closed later or left open to heal by secondary intention. The technique used to close the wound will determine the post-operative wound care and how the incision must be covered [13]. For open fractures with severe soft tissue damage, skin closure might necessitate a plastic surgical procedure using a free flap to restore the damage. In these cases, early skin closure (within a week after trauma) has a positive effect on infection rates [115]. Awaiting soft tissue coverage and preventing the wound-bed from being bacterially colonised, which might potentiate infection, demand that the would be covered. To achieve this, either negative pressure wound therapy or traditional gauze dressings can be used. Currently, for highly contaminated wounds, the use of negative wound pressure therapy is favoured, as there is evidence that infection rates are lower and, if applied for $>72$ hours, reduces the need for a soft tissue flap [116]. For closed surgical incisions, negative-pressure wound therapy is controversial, and evidence in fracture care is limited [117, 118].

Most incisions will be closed primarily after surgery and are covered by sterile wound dressings. In orthopaedic and trauma surgery, staples and sutures are most frequently used as wound-closing material. A systematic review and metaanalysis reported no significant difference between materials [119]. In both cases, the authors noted significant methodological limitations of included studies. Again, none of these 
studies was performed in a trauma population, and there is an urgent need for well-designed randomised controlled trials comparing both materials $[119,120]$. The WHO does not make any recommendations regarding the type of material; however, when sutures are used, they suggest using triclosan-coated sutures for preventing SSIs. Because the daily absorption of triclosan from these sutures is rather low, the chance of developing resistance remains low. Sutures impregnated with other antimicrobial agents are being tested [15], and wound dressings are used to provide physical support and protection from bacterial contamination and absorb exudate [121, 122]. A Cochrane review analysed several studies that assessed the effect of wound dressings in preventing SSIs. Compared with leaving the incision exposed, there was insufficient evidence supporting the hypothesis that covering the surgical incision leads to a decrease in SSI. In addition, it appears that there is no evidence for an optimal dressing (hydrocolloid, film, silver-containing, basic wound contact) to prevent SSIs. However, it should be taken into account that these studies were small and at risk for bias. Furthermore, the patient population consisted of nontrauma patients [121]. One study specifically studied the use of silver-containing dressings after acute limb injury. The authors decided that there are limited clinical trials of relevance to trauma patients and that the evidence for using silver-containing dressings in these types of injuries is lacking [123]. Future research regarding this topic is necessary to improve our knowledge with respect to musculoskeletal trauma patients.

Wound drainage Wound drains have been used to prevent fluid accumulation, and some debate remains on the difference between using and not using drains [124]. Several studies in the orthopaedic domain indicate that there is no advantage

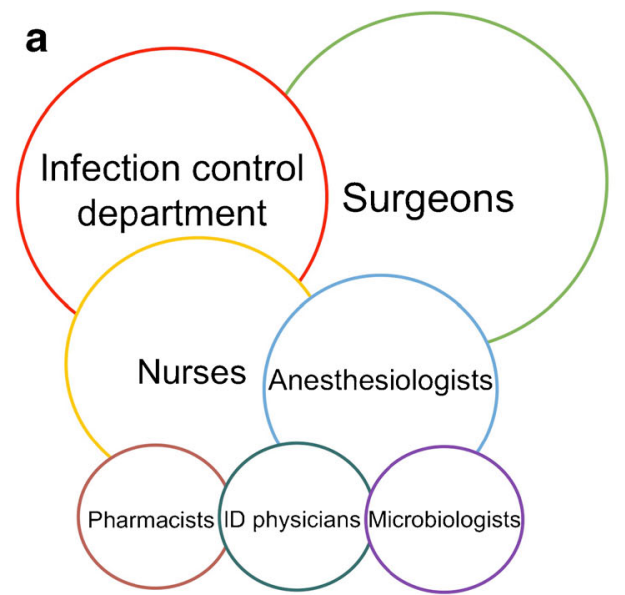

Fig. 1 Responsibility of actors involved in infection prevention versus treatment. Circle size is proportional to role importance in prevention or treatment.a Surgeons, infection-control physicians, nurses and anaesthesiologists play an important role in infection prevention. The role of pharmacists, infectious disease (ID) physicians and in using a wound drain for implant-related surgery. In a randomised controlled trial, Li et al. studied the use of wound drains in total knee arthroplasty surgery and reported no significant advantage associated with their placement [125]. Similar results were found in a systematic review and metaanalysis by Kelly et al. [126]. For musculoskeletal trauma surgery, these types of studies are again lacking.

\section{Post-operative prevention measures}

Regardless of type of postoperative care required, staff compliance with hand hygiene and aseptic procedure protocols are important throughout the entire hospital stay of the patient. Several studies addressing early versus delayed showering of patients with a surgical wound found no difference in the development of infections [127, 128]. Furthermore, studies of early versus delayed dressing removal after primary closure summarised in a Cochrane database showed no apparently significant difference between early (up to 48 hours after surgery) and delayed (beyond 48 hours) removal [122]. Those findings were based on three small randomised controlled trials, so some uncertainty remains regarding the exact timing of dressing removal. We opt to leave the wound covered for 24 to 48 hours unless the dressing is stained or in specific cases where wound observation is essential (e.g. reimplantation of an amputated limb).

\section{Discussion}

FRI remains a challenging complication. Because morbidity related to FRI remains high, it seems beneficial to aim for prevention rather than treatment of this, sometimes

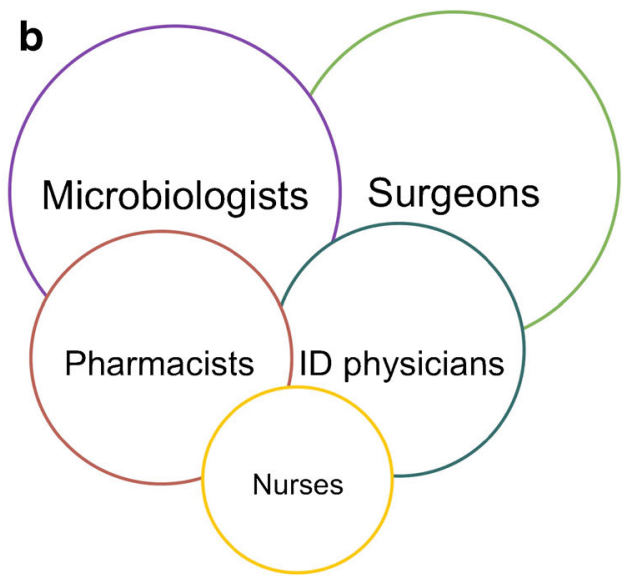

microbiologists is less distinct and is mainly limited to pre-operative antibiotic policy. b Surgeons, ID physicians, microbiologists and pharmacists all play a substantial role in the diagnosis and treatment of infection; nurses' roles are limited to correct administration of prescribed antibiotic treatment 
devastating, complication [129]. This review focuses on the fact that a multidisciplinary approach is needed to guide FRI prevention strategies, especially in a complex population like musculoskeletal trauma patients [11]. There is increasing evidence that teamwork and collaboration between healthcare workers are essential to improve outcomes $[8,130]$. The beneficial effect of a stewardship programme on infection treatment by means of antibiotic stewardship has been established. Antibiotic stewardship is defined as "coordinated interventions designed to improve and measure the appropriate use of (antibiotic) agents by promoting the selection of the optimal (antibiotic) drug regimen, including dosing, duration of therapy and route of administration" [131]. Surgeons, ID physicians and pharmacists are the core members of this programme, but microbiologists and the implementation of administrative and information technology can also be of great importance [11, 132, 133]. With its multidisciplinary approach, an antibiotic stewardship programme improves patient safety and outcome and, combined with reduced readmission rates, reduces healthcare costs without compromising quality of care [11, 132, 134].

To date, no data are available on the use and effect of such a multidisciplinary approach to infection prevention. A preventive multidisciplinary care package can be the first step towards achieving this. All above-mentioned precautions and measures to reduce the risk of SSI require the commitment of every healthcare worker involved in the care of surgical patients. However, the importance of the role of each one in infection prevention is different from those in infection treatment (Fig. 1). Indeed, when treating infection, early diagnosis and customised treatment is of critical importance, allowing microbiologists and surgeons to take the lead in consultation with ID physicians and pharmacists. Nursing staff must ensure that the antibiotic therapy is administered in accordance with the prescription, but the role of infection-control physicians is less distinct (Fig. 1b). By contrast, in infection prevention, the infection-control specialist takes the lead by setting up prevention strategies and educating the staff. Surgeons in particular, but also nurses and anaesthesiologists, are key in implementing these measures. The role of pharmacists, ID physicians and microbiologists is mainly limited to the development and continuation of preoperative (prophylactic) antibiotic policy (Fig 1a).

\section{Conclusion}

In this review, we emphasise the importance of infection prevention in musculoskeletal trauma surgery. A multidisciplinary care package is the first step towards achieving this goal.
This approach requires close cooperation between the surgeons and infection-control physicians. We also mention the importance of the new WHO global guidelines and the CDC guidelines for preventing SSI. We also emphasise the fact that data for this report are mostly based on studies regarding the development of SSIs in nontrauma patients. Similar studies are lacking for FRI prevention in the trauma population.

\section{Compliance with ethical standards}

Conflict of interest The Department of Traumatology of the University Hospitals Leuven received a research grant from Johnson \& Johnson Medical, Ethicon.

Open Access This article is distributed under the terms of the Creative Commons Attribution 4.0 International License (http:// creativecommons.org/licenses/by/4.0/), which permits unrestricted use, distribution, and reproduction in any medium, provided you give appropriate credit to the original author(s) and the source, provide a link to the Creative Commons license, and indicate if changes were made.

\section{References}

1. Hak DJ, Fitzpatrick D, Bishop JA et al (2014) Delayed union and nonunions: epidemiology, clinical issues, and financial aspects. Injury 45(Suppl 2):S3-S7. https://doi.org/10.1016/j.injury.2014.04. 002

2. Vrijens F, Hulstaert F, Gordts B et al (2009) Nosocomiale infecties in België. Impact op mortaliteit en kosten, Deel II

3. Klevens RM, Edwards JR, Richards CL et al (2007) Estimating health care-associated infections and deaths in U.S. hospitals, 2002. Public Health Rep 122:160-166

4. Olesen UK, Pedersen NJ, Eckardt $\mathrm{H}$ et al (2016) The cost of infection in severe open tibial fractures treated with a free flap. Int Orthop. https://doi.org/10.1007/s00264-016-3337-6

5. Trampuz A, Zimmerli W (2006) Diagnosis and treatment of infections associated with fracture-fixation devices. Injury 37(Suppl 2):S59-S66. https://doi.org/10.1016/j.injury.2006.04.010

6. Metsemakers WJ, Kuehl R, Moriarty TF et al (2016) Infection after fracture fixation: current surgical and microbiological concepts. Injury. https://doi.org/10.1016/j.injury.2016.09.019

7. Metsemakers WJ, Reul M, Nijs S (2015) The use of gentamicin-coated nails in complex open tibia fracture and revision cases: $\{a\}$ retrospective analysis of a single centre case series and review of the literature. Injury 46:2433-2437. https://doi.org/10.1016/j.injury.2015.09.028

8. Greene LR, Mills R, Moss R, et al (2010) Guide to the elimination of Orthopedic surgical site infections

9. Thakore RV, Greenberg SE, Shi H et al (2015) Surgical site infection in orthopedic trauma: a case-control study evaluating risk factors and cost. J Clin Orthop Trauma 6:220-226. https://doi.org/10.1016/j.jcot. 2015.04.004

10. Saddawi-konefka D, Kim HM, Chung KC et al (2015) HHS public access. Plast Reconstr Surg 122:1796-1805. https://doi.org/10.1097/ PRS.0b013e31818d69c3.A

11. Tamma PD, Cosgrove SE (2011) Antimicrobial stewardship. Infect Dis Clin N Am 25:245-260. https://doi.org/10.1016/j.idc.2010.11.011

12. Davey P, Marwick CA, Scott CL, et al (2017) Interventions to improve antibiotic prescribing practices for hospital inpatients. Cochrane Database Syst Rev 9(2):CD003543. https://doi.org/10.1002/14651858

13. Mangram AJ, Horan TC, Pearson ML et al (1999) Guideline for prevention of surgical site infection, 1999. Hospital infection control 
practices advisory committee. Infect Control Hosp Epidemiol 20:250 278, quiz 279-280. https://doi.org/10.1086/501620

14. Berrios-Torres SI, Umscheid CA, Bratzler DW et al (2017) Centers for Disease Control and Prevention guideline for the prevention of surgical site infection, 2017. JAMA Surg. https://doi.org/10.1001/jamasurg. 2017.0904

15. WHO (2016) Global guidelines for the prevention of surgical site infection. World Health Organization, Geneva

16. Metsemakers W-J, Moriarty TF, Morgenstern M et al (2016) Letter to the editor: new definition for Periprosthetic joint infection: from the workgroup of the musculoskeletal infection society. Clin Orthop Relat Res 474:2726-2727. https://doi.org/10.1007/s11999-016-5087-6

17. Bishop JA, Palanca AA, Bellino MJ, Lowenberg DW (2012) Assessment of compromised fracture healing. J Am Acad Orthop Surg 20:273-282. https://doi.org/10.5435/JAAOS-20-05-273

18. Metsemakers WJ, Kortram K, Morgenstern M et al (2017) Definition of infection after fracture fixation: a systematic review of randomized controlled trials to evaluate current practice. Injury. https://doi.org/10. 1016/j.injury.2017.02.010

19. Killian CA, Graffunder EM, Vinciguerra TJ, Venezia RA (2001) Risk factors for surgical-site infections following cesarean section. Infect Control Hosp Epidemiol 22:613-617. https://doi.org/10.1086/501831

20. Triantafyllopoulos G, Stundner O, Memtsoudis S, Poultsides LA (2015) Patient, surgery, and hospital related risk factors for surgical site infections following Total hip Arthroplasty. ScientificWorldJournal 2015:979560. https://doi.org/10.1155/2015/ 979560

21. Mabit C, Marcheix PS, Mounier M et al (2012) Impact of a surgical site infection (SSI) surveillance programme in orthopedics and traumatology. Orthop Traumatol Surg Res 98:690-695. https://doi. org/10.1016/j.otsr.2012.08.001

22. McPherson EJ, Woodson C, Holtom P et al (2002) Periprosthetic total hip infection: outcomes using a staging system. Clin Orthop Relat Res: $8-15$

23. Fehring KA, Abdel MP, Ollivier M et al (2017) Repeat two-stage exchange Arthroplasty for Periprosthetic knee infection is dependent on host grade. J Bone Joint Surg Am 99:19-24. https://doi.org/10. 2106/JBJS.16.00075

24. Chen AF, Wessel CB, Rao N (2013) Staphylococcus Aureus screening and decolonization in orthopaedic surgery and reduction of surgical site infections. Clin Orthop Relat Res 471:2383-2399. https://doi.org/10. 1007/s11999-013-2875-0

25. Watkins RR, David MZ, Salata RA (2012) Current concepts on the virulence mechanisms of meticillin-resistant Staphylococcus Aureus. J Med Microbiol 61:1179-1193. https://doi.org/10.1099/jmm.0.0435130

26. Thyagarajan D, Sunderamoorthy D, Haridas S et al (2009) MRSA colonisation in patients admitted with hip fracture: implications for prevention of surgical site infection. Acta Orthop Belg 75:252-257

27. Nixon M, Jackson B, Varghese P et al (2006) Methicillin-resistant Staphylococcus Aureus on orthopaedic wards: incidence, spread, mortality, cost and control. J Bone Joint Surg (Br) 88:812-817. https://doi. org/10.1302/0301-620X.88B6.17544

28. Walley G, Orendi J, Bridgman S et al (2009) Methicillin resistant Staphylococcus Aureus (MRSA) is not always caught on the orthopaedic ward. Acta Orthop Belg 75:245-251

29. Edmundson SP, Hirpara KM, Bennett D (2011) The effectiveness of methicillin-resistant Staphylococcus Aureus colonisation screening in asymptomatic healthcare workers in an Irish orthopaedic unit. Eur J Clin Microbiol Infect Dis 30:1063-1066. https://doi.org/10.1007/ s10096-011-1192-3

30. Dancer SJ, Christison F, Eslami A et al (2016) Is it worth screening elective orthopaedic patients for carriage of Staphylococcus Aureus? A part-retrospective case-control study in a Scottish hospital. BMJ Open. https://doi.org/10.1136/bmjopen-2016-011642
31. Bode LGM, Kluytmans JAJW, Wertheim HFL et al (2010) Preventing surgical-site infections in nasal carriers of Staphylococcus Aureus. N Engl J Med 362:9-17. https://doi.org/10.1056/NEJMoa0808939

32. Rao N, Cannella BA, Crossett LS et al (2011) Preoperative screening/ decolonization for Staphylococcus Aureus to prevent orthopedic surgical site infection: prospective cohort study with 2-year follow-up. J Arthroplast 26:1501-1507. https://doi.org/10.1016/j.arth.2011.03.014

33. van Rijen MML, Bonten M, Wenzel RP, Kluytmans JAJW (2008) Intranasal mupirocin for reduction of Staphylococcus Aureus infections in surgical patients with nasal carriage: a systematic review. J Antimicrob Chemother 61:254-261. https://doi.org/10.1093/jac/ $\mathrm{dkm} 480$

34. Bebko SP, Green DM, Awad SS (2015) Effect of a preoperative decontamination protocol on surgical site infections in patients undergoing elective orthopedic surgery with hardware implantation. JAMA Surg 150:390-395. https://doi.org/10.1001/jamasurg.2014.3480

35. WHO (2009) Guidelines on hand hygiene in health care. World Health Organ. https://doi.org/10.1086/600379

36. Burke J (2003) Infection control — a problem for patient safety. N Engl J Med 348:651-656

37. Tanner J, Swarbrook S, Stuart J, et al (2016) Surgical hand antisepsis to reduce surgical site infection (review). Cochrane Database Syst Rev https://doi.org/10.1002/14651858.CD004288.pub2.Copyright

38. Vlaams Agentschap Zorg en Gezondheid (2012) Eisenkader operatiekwartier. https://www.zorgen-gezondheid.be/sites/default/ files/atoms/files/EK\%20operatiekwartier.pdf

39. Centers for Disease Control and Prevention (2002) Guideline for hand hygiene in health-care settings: recommendations of the Healthcare Infection Control Practices Advisory Committee and the HICPAC/ SHEA/APIC/IDSA Hand Hygiene Task Force. https://www.cdc.gov/ mmwr/pdf/rr/rr5116.pdf

40. Leaper D, Burman-Roy S, Palanca A, Cullen K, Worster D, GautamAitken E, Whittle M (2008) Guideline development group. Prevention and treatment of surgical site infection: summary of NICE guidance. BMJ 28:337. https://doi.org/10.1136/bmj.a1924

41. Arrowsmith VA, Maunder JA, Sargent RJ, Taylor R (2001) Removal of nail polish and finger rings to prevent surgical infection. Cochrane Database Syst Rev CD003325. https://doi.org/10.1002/14651858. CD003325

42. Uçkay I, Hoffmeyer P, Lew D, Pittet D (2013) Prevention of surgical site infections in orthopaedic surgery and bone trauma: state-of-the-art update. J Hosp Infect 84:5-12. https://doi.org/10.1016/j.jhin.2012.12. 014

43. Parienti JJ, Thibon P, Heller R et al (2002) Hand-rubbing with an aqueous alcoholic solution vs traditional surgical hand-scrubbing and 30-day surgical site infection rates: a randomized equivalence study. JAMA 288:722-727

44. Widmer AF (2013) Surgical hand hygiene: scrub or rub? J Hosp Infect 83(Suppl 1):S35-S39. https://doi.org/10.1016/S0195-6701(13)600080

45. Kampf G, Ostermeyer C, Heeg P (2005) Surgical hand disinfection with a propanol-based hand rub: equivalence of shorter application times. J Hosp Infect 59:304-310. https://doi.org/10.1016/j.jhin.2004. 09.022

46. Lefebvre A, Saliou P, Lucet JC et al (2015) Preoperative hair removal and surgical site infections: network meta-analysis of randomized controlled trials. J Hosp Infect 91:100-108. https://doi.org/10.1016/j.jhin. 2015.06.020

47. Tanner J, Norrie P, Melen K (2011) Preoperative hair removal to reduce surgical site infection. Cochrane Database Syst Rev CD004122. https://doi.org/10.1002/14651858.CD004122.pub4

48. Dumville JC, McFarlane E, Edwards P et al (2015) Preoperative skin antiseptics for preventing surgical wound infections after clean surgery. Cochrane Database Syst Rev 4:CD003949. https://doi.org/10.1002/ 14651858.CD003949.pub4 
49. Darouiche RO, Wall MJ, Itani KMF et al (2010) Chlorhexidine-alcohol versus Povidone-iodine for surgical-site antisepsis. N Engl J Med 362: 18-26. https://doi.org/10.1056/NEJMoa0810988

50. Noorani A, Rabey N, Walsh SR, Davies RJ (2010) Systematic review and meta-analysis of preoperative antisepsis with chlorhexidine versus povidone-iodine in clean-contaminated surgery. Br J Surg 97:16141620. https://doi.org/10.1002/bjs. 7214

51. Lee I, Agarwal RK, Lee BY et al (2010) Systematic review and cost analysis comparing use of chlorhexidine with use of iodine for preoperative skin antisepsis to prevent surgical site infection. Infect Control Hosp Epidemiol 31:1219-1229. https://doi.org/10.1086/657134

52. Charehbili A, Swijnenburg R-J, van de Velde C et al (2014) A retrospective analysis of surgical site infections after chlorhexidine-alcohol versus iodine-alcohol for pre-operative antisepsis. Surg Infect 15:310 313. https://doi.org/10.1089/sur.2012.185

53. Van Laer F (2010) Chloorhexidine in alcohol versus jodiumverbindingen in alcohol. NOSO 14:13-15

54. Broach RB, Paulson EC, Scott C, Mahmoud NN (2017) Randomized controlled trial of two alcohol-based preparations for surgical site antisepsis in colorectal surgery. Ann Surg 1. https://doi.org/10.1097/SLA. 0000000000002189

55. Classen DC, Evans RS, Pestotnik SL et al (1992) The timing of prophylactic administration of antibiotics and the risk of surgical-wound infection. N Engl J Med 326:281-286. https://doi.org/10.1056/ NEJM199201303260501

56. Boxma H, Broekhuizen T, Patka P, Oosting H (1996) Randomised controlled trial of single-dose antibiotic prophylaxis in surgical treatment of closed fractures: the Dutch trauma trial. Lancet 347:11331137

57. Gillespie WJ, Walenkamp GH (2010) Antibiotic prophylaxis for surgery for proximal femoral and other closed long bone fractures. Cochrane Database Syst Rev CD000244. https://doi.org/10.1002/ 14651858.CD000244.pub2

58. Parvizi J1, Gehrke T, Chen AF (2013) Proceedings of the international consensus on periprosthetic joint infection. Bone Joint J 11:1450 1452. https://doi.org/10.1302/0301-620X.95B11.33135

59. Kasatpibal N, Whitney JD, Dellinger EP et al (2016) Failure to Redose antibiotic prophylaxis in long surgery increases risk of surgical site infection. Surg Infect. https://doi.org/10.1089/sur.2016.164

60. Gatell JM, Garcia S, Lozano L et al (1987) Perioperative cefamandole prophylaxis against infections. J Bone Joint Surg Am 69:1189-1193

61. Engesaeter LB, Lie SA, Espehaug B et al (2003) Antibiotic prophylaxis in total hip arthroplasty: effects of antibiotic prophylaxis systemically and in bone cement on the revision rate of 22,170 primary hip replacements followed 0-14 years in the Norwegian Arthroplasty register. Acta Orthop Scand 74:644-651. https://doi.org/10.1080/ 00016470310018135

62. Bratzler DW, Dellinger EP, Olsen KM et al (2013) Clinical practice guidelines for antimicrobial prophylaxis in surgery. Surg Infect 14:73156. https://doi.org/10.1089/sur.2013.9999

63. Muller A, Leroy J, Hénon T et al (2015) Surgical antibiotic prophylaxis compliance in a university hospital. Anaesth Crit Care Pain Med 34: 289-294. https://doi.org/10.1016/j.accpm.2015.04.004

64. Halawi MJ, Morwood MP (2015) Acute Management of Open Fractures: an evidence-based review. Orthopedics 38:e1025-e1033. https://doi.org/10.3928/01477447-20151020-12

65. Dunkel N, Pittet D, Tovmirzaeva L et al (2013) Short duration of antibiotic prophylaxis in open fractures does not enhance risk of subsequent infection. Bone Joint J 95-B:831-837. https://doi.org/10. 1302/0301-620X.95B6.30114

66. Rodriguez L, Jung HS, Goulet JA et al (2014) Evidence-based protocol for prophylactic antibiotics in open fractures: improved antibiotic stewardship with no increase in infection rates. J Trauma Acute Care Surg 77:400-407; discussion 407-408; quiz 524. https://doi.org/10.1097/ TA. 0000000000000398
67. Singh K, Bauer JM, LaChaud GY et al (2015) Surgical site infection in high-energy peri-articular tibia fractures with intra-wound vancomycin powder: a retrospective pilot study. J Orthop Traumatol 16:287-291. https://doi.org/10.1007/s10195-015-0352-0

68. Ostermann PA, Seligson D, Henry SL (1995) Local antibiotic therapy for severe open fractures. A review of 1085 consecutive cases. J Bone Joint Surg Br 77:93-97

69. Metsemakers W-J, Moriarty TF, Nijs S et al (2016) Influence of implant properties and local delivery systems on the outcome in operative fracture care. Injury 47:595-604. https://doi.org/10.1016/j.injury.2016. 01.019

70. Salassa TE, Swiontkowski MF (2014) Surgical attire and the operating room: role in infection prevention. J Bone Joint Surg Am 96:14851492. https://doi.org/10.2106/JBJS.M.01133

71. Lipp A, Edwards P (2014) Disposable surgical face masks for preventing surgical wound infection in clean surgery. Cochrane Database Syst Rev CD002929. https://doi.org/10.1002/14651858. CD002929.pub2

72. Vincent M, Edwards P (2016) Disposable surgical face masks for preventing surgical wound infection in clean surgery. Cochrane Database Syst Rev 4:CD002929. https://doi.org/10.1002/14651858. CD002929.pub3

73. Young SW, Zhu M, Shirley OC et al (2016) Do "surgical helmet systems" or "body exhaust suits" affect contamination and deep infection rates in Arthroplasty? A systematic review. J Arthroplast 31:225233. https://doi.org/10.1016/j.arth.2015.07.043

74. Hooper GJ, Rothwell AG, Frampton C, Wyatt MC (2011) Does the use of laminar flow and space suits reduce early deep infection after total hip and knee replacement?: the ten-year results of the New Zealand joint registry. J Bone Joint Surg Br 93:85-90. https://doi.org/10.1302/ 0301-620X.93B1.24862

75. Hosseini P, Mundis GM, Eastlack R et al (2016) Do longer surgical procedures result in greater contamination of surgeons' hands? Clin Orthop Relat Res 474:1707-1713. https://doi.org/10.1007/s11999016-4832-1

76. Hübner N-O, Goerdt A-M, Stanislawski N et al (2010) Bacterial migration through punctured surgical gloves under real surgical conditions. BMC Infect Dis 10:192. https://doi.org/10.1186/1471-2334-10192

77. Beldame J, Lagrave B, Lievain L et al (2012) Surgical glove bacterial contamination and perforation during total hip arthroplasty implantation: when gloves should be changed. Orthop Traumatol Surg Res 98: 432-440. https://doi.org/10.1016/j.otsr.2011.10.015

78. Tanner J, Parkinson H (2006) Double gloving to reduce surgical crossinfection. Cochrane Database Syst Rev 19(3):CD003087. https://doi. org/10.1002/14651858.CD003087

79. Tumia N, Ashcroft GP (2002) Convection warmers-a possible source of contamination in laminar airflow operating theatres? J Hosp Infect 52:171-174

80. Bédard M, Pelletier-Roy R, Angers-Goulet M et al (2015) Traffic in the operating room during joint replacement is a multidisciplinary problem. Can J Surg 58:232-236

81. Tang JW, Eames I, Li Y et al (2005) Door-opening motion can potentially lead to a transient breakdown in negative-pressure isolation conditions: the importance of vorticity and buoyancy airflows. J Hosp Infect 61:283-286. https://doi.org/10.1016/j.jhin.2005.05.017

82. Birgand G, Saliou P, Lucet J-C (2015) Influence of staff behavior on infectious risk in operating rooms: what is the evidence? Infect Control Hosp Epidemiol 36:93-106. https://doi.org/10.1017/ice.2014.9

83. Kakwani RG, Yohannan D, Wahab KHA (2007) The effect of laminar air-flow on the results of Austin-Moore hemiarthroplasty. Injury 38: 820-823. https://doi.org/10.1016/j.injury.2006.09.025

84. Ahl T, Dalén N, Jörbeck H, Hoborn J (1995) Air contamination during hip and knee arthroplasties. Horizontal laminar flow randomized vs. conventional ventilation. Acta Orthop Scand 66:17-20 
85. Talon D, Schoenleber T, Bertrand X, Vichard P (2006) Performances of different types of airflow system in operating theatre. Ann Chir 131: 316-321. https://doi.org/10.1016/j.anchir.2006.02.002

86. Kwasny O, Scharf W, Schemper M (1989) Prevention of infection in implantation of femur head prostheses. Langenbecks Arch Chir 374: $227-231$

87. Madhavan P, Blom A, Karagkevrakis B et al (1999) Deterioration of theatre discipline during total joint replacement-have theatre protocols been abandoned? Ann R Coll Surg Engl 81:262-265

88. Dalstrom DJ, Venkatarayappa I, Manternach AL et al (2008) Timedependent contamination of opened sterile operating-room trays. J Bone Joint Surg Am 90:1022-1025. https://doi.org/10.2106/JBJS.G. 00689

89. Webster J, Alghamdi A (2015) Use of plastic adhesive drapes during surgery for preventing surgical site infection. Cochrane Database Syst Rev 4:CD006353. https://doi.org/10.1002/14651858.CD006353.pub4

90. Meka PN, Khullar P, Anand VJ (2004) To compare the superiority of electrocautery over the traditional scalpel for skin incisions. J Surg Res. https://doi.org/10.1016/j.jss.2004.07.238

91. Kates SL, Borens O (2017) Principles of orthopedic infection management. Thieme

92. Peng RY, Bongard FS (1999) Hypothermia in trauma patients. J Am Coll Surg 188:685-696

93. Kellam MD, Dieckmann LS, Austin PN (2013) Forced-air warming devices and the risk of surgical site infections. AORN J 98:354-369. https://doi.org/10.1016/j.aorn.2013.08.001

94. Kurz A, Sessler DI, Lenhardt R (1996) Perioperative normothermia to reduce the incidence of surgical-wound infection and shorten hospitalization. Study of wound infection and temperature group. N Engl J Med 334:1209-1215. https://doi.org/10.1056/ NEJM199605093341901

95. Forbes SS, McLean RF (2013) Review article: the anesthesiologist's role in the prevention of surgical site infections. Can J Anaesth 60:176183. https://doi.org/10.1007/s12630-012-9858-6

96. Forbes SS, Eskicioglu C, Nathens AB et al (2009) Evidence-based guidelines for prevention of Perioperative hypothermia. J Am Coll Surg 209:492-503.e1. https://doi.org/10.1016/j.jamcollsurg.2009.07. 002

97. Brown MJ, Curry TB, Hyder JA et al (2017) Intraoperative hypothermia and surgical site infections in patients with class I/clean wounds: a case-control study. J Am Coll Surg 224:160-171. https://doi.org/10. 1016/j.jamcollsurg.2016.10.050

98. Wood AM, Moss C, Keenan A et al (2014) Infection control hazards associated with the use of forced-air warming in operating theatres. J Hosp Infect 88:132-140. https://doi.org/10.1016/j.jhin.2014.07.010

99. McGovern PD, Albrecht M, Belani KG et al (2011) Forced-air warming and ultra-clean ventilation do not mix: an investigation of theatre ventilation, patient warming and joint replacement infection in orthopaedics. J Bone Joint Surg Br 93:1537-1544. https://doi.org/ 10.1302/0301-620X.93B11.27124

100. Golden SH, Peart-Vigilance C, Kao WH, Brancati FL (1999) Perioperative glycemic control and the risk of infectious complications in a cohort of adults with diabetes. Diabetes Care 22:1408-1414

101. Kadoi Y (2010) Anesthetic considerations in diabetic patients. Part II: intraoperative and postoperative management of patients with diabetes mellitus. J Anesth 24:748-756. https://doi.org/10.1007/s00540-0100988-0

102. Zalavras CG (2017) Prevention of infection in open fractures. Infect Dis Clin N Am. https://doi.org/10.1016/j.idc.2017.01.005

103. Bhandari M, Adili A, Schemitsch EH (2001) The efficacy of lowpressure lavage with different irrigating solutions to remove adherent bacteria from bone. J Bone Joint Surg Am 83-A:412-419

104. Crowley DJ, Kanakaris NK, Giannoudis PV (2007) Irrigation of the wounds in open fractures. J Bone Joint Surg Br Vol 89-B:580-585. https://doi.org/10.1302/0301-620X.89B5.19286
105. Kaysinger KK, Nicholson NC, Ramp WK, Kellam JF (1995) Toxic effects of wound irrigation solutions on cultured tibiae and osteoblasts. J Orthop Trauma 9:303-311

106. Lineaweaver W, Howard R, Soucy D et al (1985) Topical antimicrobial toxicity. Arch Surg 120:267-270

107. Durani P, Leaper D (2008) Povidone-iodine: use in hand disinfection, skin preparation and antiseptic irrigation. Int Wound J 5:376-387. https://doi.org/10.1111/j.1742-481X.2007.00405.x

108. Cheng M-T, Chang M-C, Wang S-T et al (2005) Efficacy of dilute betadine solution irrigation in the prevention of postoperative infection of spinal surgery. Spine (Phila Pa 1976) 30:1689-1693

109. Chang F-Y, Chang M-C, Wang S-T et al (2006) Can povidone-iodine solution be used safely in a spinal surgery? Eur Spine J 15:1005-1014. https://doi.org/10.1007/s00586-005-0975-6

110. Rogers DM, Blouin GS, O’Leary JP (1983) Povidone-iodine wound irrigation and wound sepsis. Surg Gynecol Obstet 157:426-430

111. Sindelar WF, Mason GR (1979) Irrigation of subcutaneous tissue with povidone-iodine solution for prevention of surgical wound infections. Surg Gynecol Obstet 148:227-231

112. Dirschl DR, Duff GP, Dahners LE et al High pressure pulsatile lavage irrigation of intraarticular fractures: effects on fracture healing. J Orthop Trauma 12:460-463

113. Owens BD, White DW, Wenke JC (2009) Comparison of irrigation solutions and devices in a contaminated musculoskeletal wound survival model. J Bone Joint Surg Am 91:92-98. https://doi.org/10.2106/ JBJS.G.01566

114. Investigators FLOW (2015) A trial of wound irrigation in the initial management of open fracture wounds. N Engl J Med 373: 151014073840006. https://doi.org/10.1056/NEJMoa1508502

115. Olesen UK, Juul R, Bonde CT et al (2015) A review of forty five open tibial fractures covered with free flaps. Analysis of complications, microbiology and prognostic factors. Int Orthop 39:1159-1166. https:// doi.org/10.1007/s00264-015-2712-Z

116. Schlatterer DR, Hirschfeld AG, Webb LX (2015) Negative pressure wound therapy in grade IIIB Tibial fractures: fewer infections and fewer flap procedures? Clin Orthop Relat Res 473:1802-1811. https://doi.org/10.1007/s11999-015-4140-1

117. Crist BD, Oladeji LO, Khazzam M et al (2017) Role of acute negative pressure wound therapy over primarily closed surgical incisions in acetabular fracture ORIF: a prospective randomized trial. Injury. https://doi.org/10.1016/j.injury.2017.04.055

118. Scalise A, Calamita R, Tartaglione C et al (2016) Improving wound healing and preventing surgical site complications of closed surgical incisions: a possible role of Incisional negative pressure wound therapy. A systematic review of the literature. Int Wound J 13:1260-1281. https://doi.org/10.1111/iwj.12492

119. Krishnan R, MacNeil SD, Malvankar-Mehta MS (2016) Comparing sutures versus staples for skin closure after orthopaedic surgery: systematic review and meta-analysis. BMJ Open 6:e009257. https://doi. org/10.1136/bmjopen-2015-009257

120. Smith TO, Sexton D, Mann C, Donell S (2010) Sutures versus staples for skin closure in orthopaedic surgery: meta-analysis. BMJ 340

121. Dumville JC, Gray TA, Walter CJ et al (2016) Dressings for the prevention of surgical site infection. Cochrane Database Syst Rev 12: CD003091. https://doi.org/10.1002/14651858.CD003091.pub4

122. Toon CD, Lusuku C, Ramamoorthy R et al (2015) Early versus delayed dressing removal after primary closure of clean and clean-contaminated surgical wounds. Cochrane Database Syst Rev 9:CD010259. https:// doi.org/10.1002/14651858.CD010259.pub3

123. Eardley WGP, Watts SA, Clasper JC (2012) Extremity trauma, dressings, and wound infection: should every acute limb wound have a silver lining? Int J Low Extrem Wounds 11:201-212. https://doi.org/ $10.1177 / 1534734612457028$

124. Clifton R, Haleem S, McKee A, Parker MJ (2008) Closed suction surgical wound drainage after hip fracture surgery: a systematic review 
and meta-analysis of randomised controlled trials. Int Orthop 32:723727. https://doi.org/10.1007/s00264-007-0420-z

125. Li C, Nijat A, Askar M (2011) No clear advantage to use of wound drains after unilateral total knee arthroplasty: a prospective randomized, controlled trial. J Arthroplast 26:519-522. https://doi.org/10. 1016/j.arth.2010.05.031

126. Kelly EG, Cashman JP, Imran FH et al (2014) Systematic review and meta-analysis of closed suction drainage versus non-drainage in primary hip arthroplasty. Surg Technol Int 24:295-301

127. Yu AL, Alfieri DC, Bartucci KN et al (2016) Wound hygiene practices after Total knee Arthroplasty: does it matter? J Arthroplast 31:22562259. https://doi.org/10.1016/j.arth.2016.03.040

128. Dayton P, Feilmeier M, Sedberry S (2013) Does postoperative showering or bathing of a surgical site increase the incidence of infection? A systematic review of the literature. J Foot Ankle Surg 52:612614. https://doi.org/10.1053/j.jfas.2013.02.016

129. Metsemakers W (2015) Long bone fractures in (poly)trauma patients: risk analyses of muskuloskeletal complications and strategies to prevent them (Thesis)

130. Greene LR (2012) Guide to the elimination of orthopedic surgery surgical site infections: an executive summary of the Association for
Professionals in infection control and epidemiology elimination guide. Am J Infect Control 40:384-386. https://doi.org/10.1016/j.ajic.2011. 05.011

131. Barlam TF, Cosgrove SE, Abbo LM et al (2016) Executive summary: implementing an antibiotic stewardship programme: guidelines by the Infectious Diseases Society of America and the Society for Healthcare Epidemiology of America. Clin Infect Dis 62:1197-1202. https://doi. org/10.1093/cid/ciw217

132. Goff DA, Kullar R, Goldstein EJC et al (2016) A global call from five countries to collaborate in antibiotic stewardship: united we succeed, divided we might fail. Lancet Infect Dis. https://doi.org/10.1016/ S1473-3099(16)30386-3

133. Baysari MT, Lehnbom EC, Li L et al (2016) The effectiveness of information technology to improve antimicrobial prescribing in hospitals: a systematic review and meta-analysis. Int J Med Inform 92:1534. https://doi.org/10.1016/j.ijmedinf.2016.04.008

134. Karanika S, Paudel S, Grigoras C et al (2016) Systematic review and meta-analysis of clinical and economic outcomes from the implementation of hospital-based antimicrobial stewardship programmes. Antimicrob Agents Chemother 60:4840-4852. https://doi.org/10. 1128/AAC.00825-16 